\title{
Prefrontal Cortex Deactivation in Macaques Alters Activity in the Superior Colliculus and Impairs Voluntary Control of Saccades
}

\author{
Michael J. Koval, ${ }^{1}$ Stephen G. Lomber, ${ }^{1,2,3}$ and Stefan Everling ${ }^{1,2,3,4}$ \\ ${ }^{1}$ Graduate Program in Neuroscience, and Departments of ${ }^{2}$ Physiology and Pharmacology, and ${ }^{3}$ Psychology, University of Western Ontario, London, Ontario \\ N6A 3K7, Canada, and ${ }^{4}$ Robarts Research Institute, London, Ontario N6A 5K8, Canada
}

The cognitive control of action requires both the suppression of automatic responses to sudden stimuli and the generation of behavior specified by abstract instructions. Though patient, functional imaging and neurophysiological studies have implicated the dorsolateral prefrontal cortex (dlPFC) in these abilities, the mechanism by which the dlPFC exerts this control remains unknown. Here we examined the functional interaction of the dIPFC with the saccade circuitry by deactivating area 46 of the dlPFC and measuring its effects on the activity of single superior colliculus neurons in monkeys performing a cognitive saccade task. Deactivation of the dlPFC reduced preparatory activity and increased stimulus-related activity in these neurons. These changes in neural activity were accompanied by marked decreases in task performance as evidenced by longer reaction times and more task errors. The results suggest that the dlPFC participates in the cognitive control of gaze by suppressing stimulus-evoked automatic saccade programs.

\section{Introduction}

We often react to sudden changes in our environment by looking toward them. While this rapid orienting response may be advantageous in certain situations, it also detracts from ongoing behavior. Therefore, we can decide to ignore sensory events and instead react to stimuli or conduct actions that are of relevance to the achievement of our current behavioral goals. The ability to suppress automatic responses and to filter out unwanted signals is thought to depend on the dorsolateral prefrontal cortex (dlPFC) (Miller and Cohen, 2001).

The antisaccade task is a particularly useful paradigm for testing response suppression and voluntary saccade generation in clinical populations (Everling and Fischer, 1998; Broerse et al., 2001; Hutton and Ettinger, 2006). The task requires subjects to suppress a saccade toward a flashed visual stimulus in favor of a saccade toward the opposite uncued direction. Patients with prefrontal lesions that involve Brodmann's area 46 (Guitton et al., 1985; Pierrot-Deseilligny et al., 1991, 2003; Walker et al., 1998; Ploner et al., 2005) and disorders that impair prefrontal functions, like schizophrenia, have longer reaction times for antisaccades and often fail to suppress a saccade toward the flashed stimulus (Fukushima et al., 1988, 1990). Moreover, functional

\footnotetext{
Received March 11, 2011; revised April 20, 2011; accepted April 25, 2011

Author contributions: S.E. designed research; M.J.K., S.G.L., and S.E. performed research; S.G.L. contributed unpublished reagents/analytic tools; M.J.K. and S.E. analyzed data; S.G.L. and S.E. wrote the paper.

This research was supported by a grant from the Canadian Institutes of Health Research to S.E. and S.G.L. We thank S. Hughes, B. Soper, and A. McMillan for excellent surgical and technical assistance. We are also grateful to J. Gati and R. Menon for help in MR imaging prior to the surgery.

Correspondence should be addressed to Dr. Stefan Everling, The Centre for Brain and Mind, Robarts Research Institute, 100 Perth Drive, London, 0N N6A 5K8, Canada. E-mail: severlin@uwo.ca.

DOI:10.1523/JNEUROSCI.1258-11.2011

Copyright $\odot 2011$ the authors $\quad 0270-6474 / 11 / 318659-10 \$ 15.00 / 0$
}

imaging studies in humans (Sweeney et al., 1996; DeSouza et al., 2003; Ford et al., 2005; Dyckman et al., 2007; Brown et al., 2008) have found higher activations in the dlPFC, in particular in Brodmann's area 46, for the performance of antisaccades compared with saccades toward visual stimuli (prosaccades), a pattern that is absent in patients with schizophrenia (McDowell et al., 2002). A unilateral pharmacological deactivation study of sites in the ventral bank of the principal sulcus in monkeys has reported impairments in the antisaccade task (Condy et al., 2007), and single-unit recording studies in monkeys have found taskselective activity task in dlPFC neurons in this task (Funahashi et al., 1993; Everling and Desouza, 2005). A subset of dlPFC neurons sends these signals directly to the superior colliculus (SC) (Johnston and Everling, 2006b), a vital node in the saccade network (Wurtz and Goldberg, 1989).

Saccade neurons in the SC are strongly modulated by the antisaccade task, by exhibiting reduced preparatory activity, reduced stimulus-related activity, and reduced motor activity (Everling et al., 1999). Therefore, it has been proposed that a general imbalance in favor of motor preparation over inhibitory processes may account for the poor voluntary control over reflexive responses associated in prefrontal disorders (Everling et al., 1998; Munoz and Everling, 2004). This hypothesis, however, fails to explain the long reaction time of saccades in these disorders. Alternatively, it has been proposed that response errors occur when a stopping signal is generated too late (Guitton et al., 1985; Pierrot-Deseilligny et al., 2003).

To seek the neural mechanism for increased reaction times and error rates in prefrontal disorders, we recorded singleneuron activity in the SC while we deactivated area 46 of the dlPFC using chronically implanted cryoloops (Lomber et al., 1999) in the left and right principal sulcus. 


\section{Materials and Methods}

Surgery. Two male macaque monkeys (Macaca mulatta) were prepared for chronic dlPFC deactivation experiments and single-neuron recordings in the SC using previously described techniques (Johnston and Everling, 2006b). All procedures were performed in accordance with the guidelines of the Canadian Council of Animal Care Policy on the Use of Laboratory Animals and a protocol approved by the Animal Use Subcommittee of the University of Western Ontario Council on Animal Care. Briefly, monkeys underwent two aseptic surgical procedures. Animals received analgesics and antibiotics postoperatively and were closely monitored by a university veterinarian. In the first surgery, a plastic head restraint and a recording chamber were implanted. The recording chamber was centered on the midline and tilted $38^{\circ}$ posterior of vertical to allow recordings from neurons in the superior colliculus. Monkeys then underwent training on the behavioral paradigm. Once the animals were proficient on the paradigm, anatomical MR images were obtained to visualize the location of the implanted recording chambers and the shape of the principal sulci. Animals then underwent a second surgery in which stainless steel cryoloops $(6 \times 3 \mathrm{~mm})$ were implanted bilaterally into the posterior portion of the principal sulcus in each animal (Fig. 1A). The technical details of the cryoloop technique have been described before (Lomber et al., 1999).

Task. During each experiment, the response field (RF) of an isolated SC neuron was mapped, and the animal initiated a task with randomly interleaved prosaccade and antisaccade trials. Each trial began with the presentation of a colored central fixation point (FP). For monkey A, a green FP signaled a prosaccade trial and a red FP signaled an antisaccade trial. The color instructions were reversed for monkey B. On half the trials, the color cue remained visible throughout the task ("rule-visible condition") (Fig. 2A). On the other half of trials, the FP changed to yellow 500-700 ms before stimulus presentation on prosaccade and antisaccade trials, requiring the monkeys to maintain the task rule ("rulememorized condition") (Fig. 2B). A white visual stimulus then randomly appeared with equal probability either in the RF of the neuron or at the mirror location. Monkeys received a juice reward if they looked toward the stimulus on prosaccade trials and away from the stimulus to its mirror location on antisaccade trials.

Prefrontal deactivations. Although reversible pharmacological deactivations are frequently used to investigate the role of cortical or subcortical areas in the control of behavior, these techniques are less suited for combined deactivations and neural recordings. Lidocaine as a sodium channel blocker also inactivates axons that pass through the area. Muscimol as a GABA agonist does not inactivate passing fibers but it lasts for several hours, preventing the observation of functional recovery following inactivation. The main disadvantage of pharmacological inactivations is that often multiple injections are necessary to obtain behavioral effects (Wardak et al., 2002). Even then the effects are often spatially very localized, making it extremely difficult to match the response field of a neuron with the inactivated spatial region in combined deactivation and recoding studies. A further shortcoming of this technique is that it is very difficult to inactive a cortical area bilaterally. The effect of unilateral inactivation, however, often seems to be related to a shift in the balance between the two hemispheres (Schiller and Chou, 1998; Wardak et al., 2006), thereby creating neglect (Kinsbourne, 1977), which might mask other more specific symptoms.

Cooling has been used in several studies to temporarily and reversibly deactivate the PFC (Fuster and Alexander, 1970; Alexander and Fuster, 1973; Bauer and Fuster, 1976; Fuster et al., 1985; Shindy et al., 1994; Chafee and Goldman-Rakic, 2000). Cortical cells are depolarized between 20 and $29^{\circ} \mathrm{C}$, and the action potentials of these neurons become broad, small in amplitude, and less frequent, and many neurons are

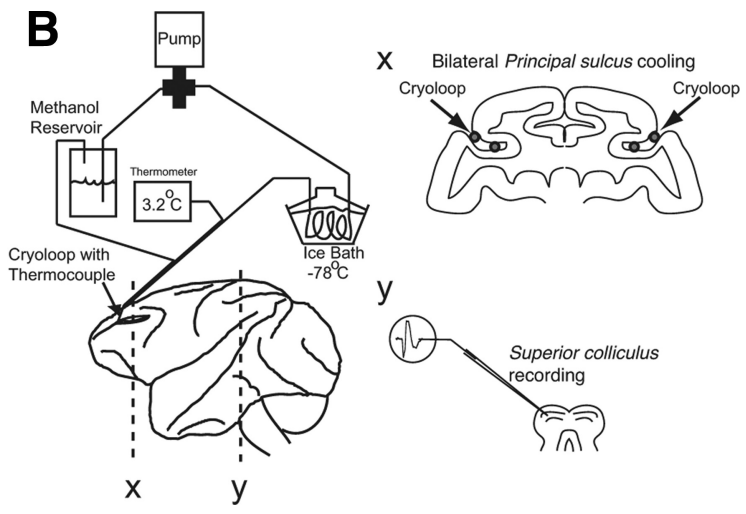

Bilateral Principal sulcus coolin

x y

\section{.}

setup. $\boldsymbol{A}$, Cryoloop to be implanted in left principal sulcus. Anterior and posterior refer to the orientation of the loop in the principal sulcus. $\boldsymbol{B}$, The dIPFC was bilaterally deactivated by pumping chilled methanol through cryoloops implanted in the left and right principal sulci while single-neuron activity was recorded in the $S C$. The schematic shows a lateral view of the macaque brain with implanted cryoloops in coronal section $(\mathrm{x})$ and single-neuron recordings in the SC in coronal section (y).
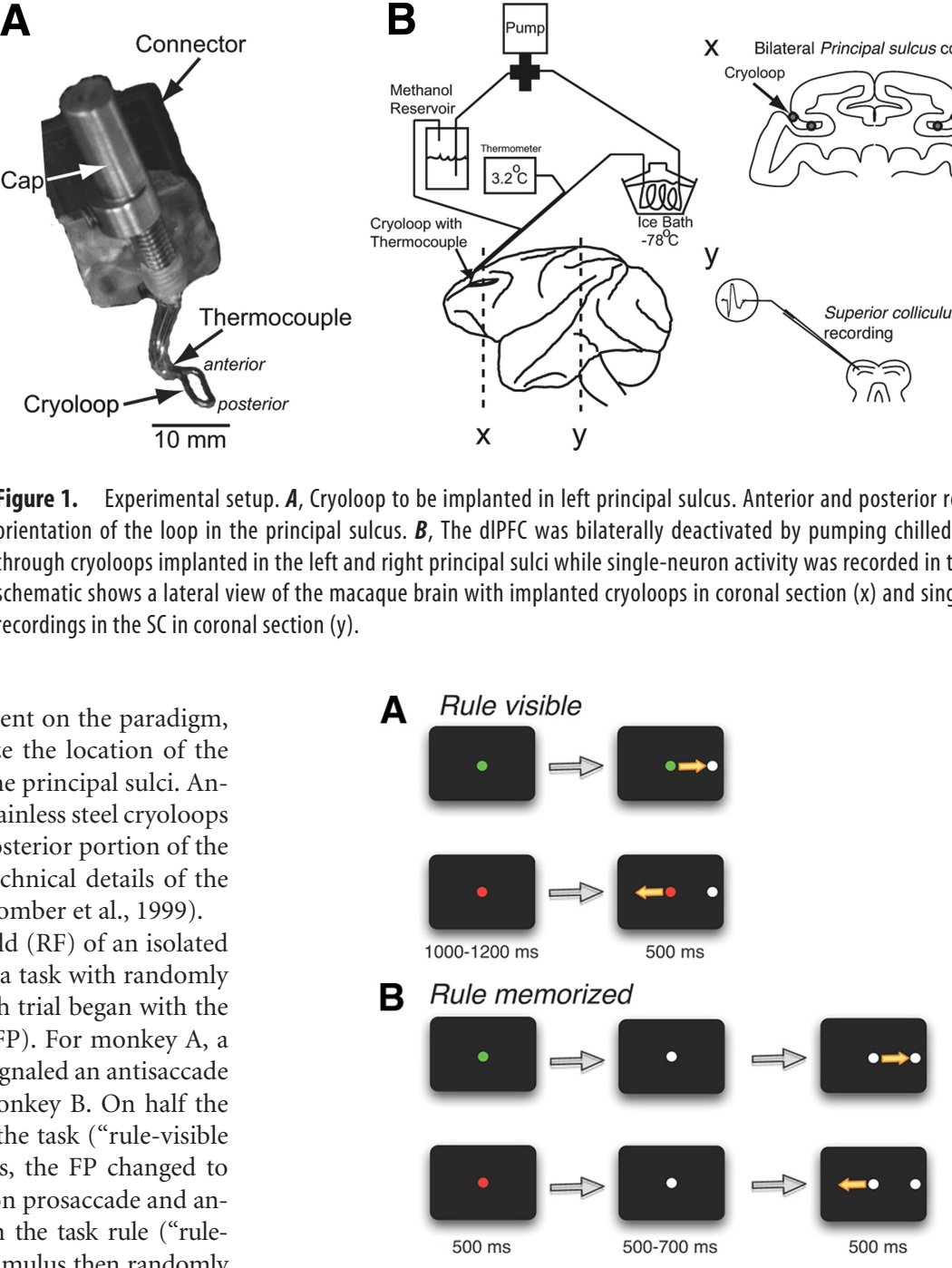

Figure 2. Experimental paradigm. $\boldsymbol{A}$, Rule-visible task. Each trial began with an FP signaling, by its color, a prosaccade or antisaccade trial. A stimulus then appeared either in the RF of the neuron or opposite to the RF on the other side. $\boldsymbol{B}$, Rule-memorized task. Same as $\boldsymbol{A}$, but the color of the FP changed to a neutral color 500-700 ms before stimulus presentation. This required the monkey to briefly memorize the task rule.

reduced to complete silence in extracellular recordings (Moseley et al., 1972a,b; Lomber et al., 1999). Previous studies that used prefrontal cortical cooling used thermoelectric coolers attached to a cooling probe that rested on the dura. A disadvantage of this approach is that the deactivated area is large and that it is very difficult to fully inactivate cortical tissue deep in a sulcus. Here we implanted cryoloops directly in the principal sulcus and therefore limited prefrontal deactivations to area 46 (Fig. 1). Chilled methanol pumped through a cryoloop deactivates adjacent cortical tissue by disrupting local synaptic activity but not axonal fibers of passage.

Cryoloops were constructed from 23 gauge hypodermic stainless steel tubing and were custom designed to conform to the shape of the principal sulci (Fig. 1A). The procedures for the manufacturing, surgery, and use of cryoloops have been described in detail (Lomber et al., 1999). Room temperature methanol was pumped through Teflon tubing that passed through a methanol ice bath, which was reduced to subzero temperatures by the addition of dry ice. Chilled methanol pumped through a cryoloop was then returned to the same reservoir from which it came. Cryoloop temperature was monitored by an attached microthermocouple. Each cooling session started with a precooling period during which the pump was turned off for 10-15 min. The cooling period began when the pump was turned on. It took on average $85 \mathrm{~s}$ to bring the 
Table 1. Behavioral effects of dIPFC deactivation

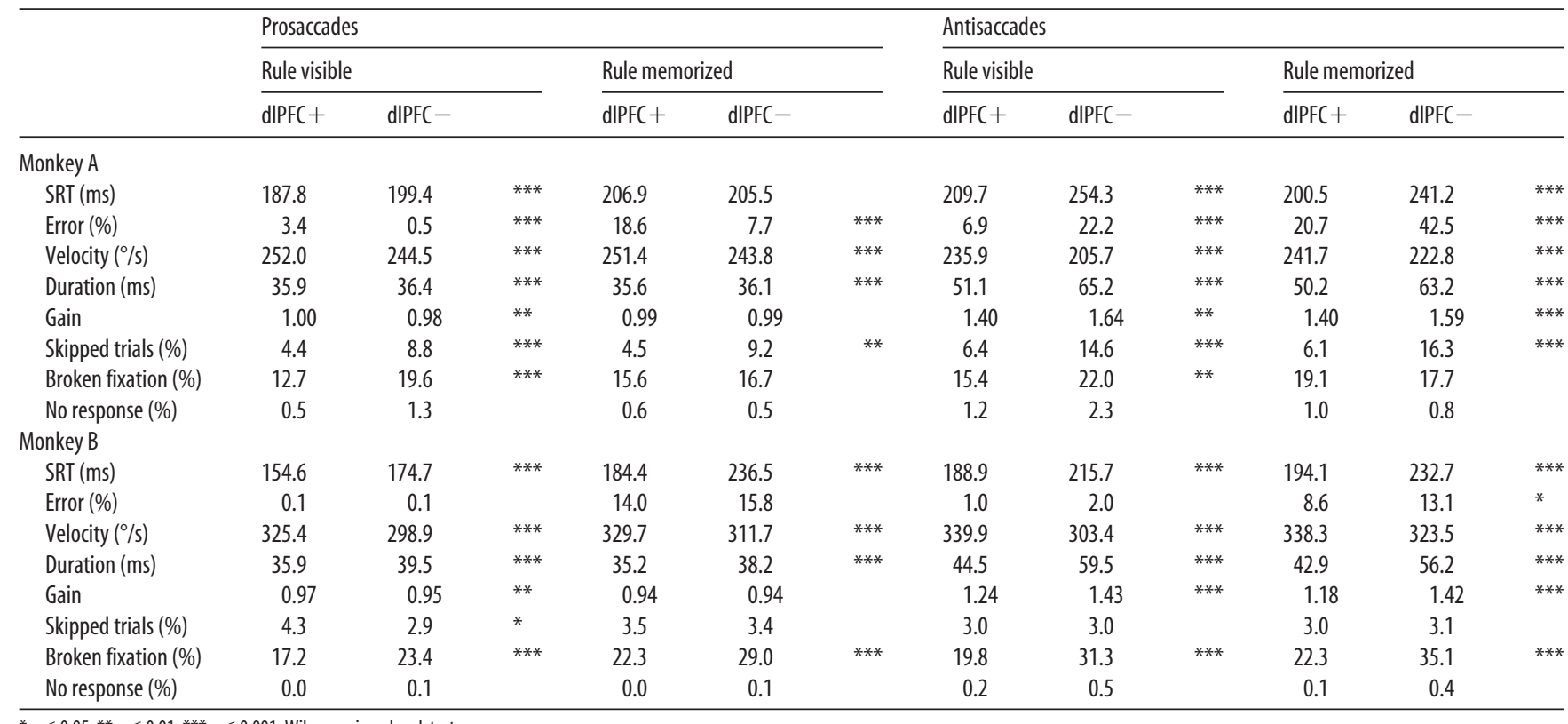

${ }^{*} p<0.05,{ }^{* *} p<0.01,{ }^{* * *} p<0.001$, Wilcoxon signed rank test.

temperature of the loops down to $3^{\circ} \mathrm{C}$. We excluded the first 4 min after the pumps were turned on to ensure that the cortical tissue adjacent to the cryoloop was cooled below $20^{\circ} \mathrm{C}$, the temperature at which neurons are deactivated (Adey, 1974). Cortical temperature, however, increases rapidly with distance from a cryoloop: the extent of inactivated tissue is limited to a range of $2 \mathrm{~mm}$ when cryoloop temperature is reduced to $1^{\circ} \mathrm{C}$. Therefore, we maintained cryoloop temperature in the range of $1-3^{\circ} \mathrm{C}$ to inactivate as large an area of cortical tissue as possible while avoiding potentially harmful subzero temperatures at the cortical surface. Cryoloop temperature was controlled by adjusting the flow rate of the pump, and maintained in the range of $1-3^{\circ} \mathrm{C}$ for between 10 and $15 \mathrm{~min}$. The pumps were then turned off. The temperature of the cryoloops returned to $30^{\circ} \mathrm{C}$ within $40 \mathrm{~s}$. The first $3 \mathrm{~min}$ after the pumps were turned off were excluded from all data analysis.

Recording method. Standard electrophysiological techniques were used to record single-neuron activity in the intermediate layers of the SC using a Plexon MAP system (Johnston and Everling, 2006b). We only included neurons in our analysis that did not show any significant differences in activity in the $500 \mathrm{~ms}$ period before stimulus presentation between precooling trials and postcooling trials ( $t$ test, $p>0.05$ ) to ensure that their isolation did not change during the recording session. Horizontal and vertical eye positions were recorded at $500 \mathrm{~Hz}$ using an Eyelink II system (SR Research).

Spike density function. To evaluate the relationship between neural activity and stimulus onset and saccade onset, continuous spike density functions were constructed. The activation waveform was obtained by convolving each spike with an asymmetric function that resembled a postsynaptic potential (Hanes and Schall, 1996; Thompson et al., 1996; Everling et al., 1999). The advantage of this function over a standard Gaussian function (Richmond and Optican, 1987) is that a spike only exerts an effect forward and not backward in time.

Time course of dlPFC deactivation. To determine the time course of the effects of dlPFC deactivation on the population of SC neurons, we performed sliding receiver operating characteristic (ROC) analyses. For the time course of dlPFC deactivation on SC activity relative to stimulus onset, the ROC value was calculated for a $10 \mathrm{~ms}$ epoch (centered around the time point) starting from $200 \mathrm{~ms}$ before peripheral stimulus onset using the convolved spike trains. This analysis was repeated in $1 \mathrm{~ms}$ increments until $300 \mathrm{~ms}$ after stimulus presentation. For the time course of dlPFC deactivation relative to saccade onset, the analysis was conducted starting $200 \mathrm{~ms}$ before saccade onset to $100 \mathrm{~ms}$ after saccade onset. An ROC time course was calculated for each neuron and then averaged separately across all SC neurons. To test whether the ROC values were significant at any time points for the population of SC neurons, we conducted bootstrap analyses. To this end, the following procedure was repeated 10,000 times: for each neuron, a random decision was made to either exchange the two activation conditions (dlPFC+ and dlPFC-) ( $50 \%$ probability) or leave them unchanged ( $50 \%$ probability). Each of the 10,000 repetitions of the analysis, performed on all SC neurons, yielded a single average time course. The distribution of the 10,000 average ROC values at each point in time was then used to calculate the 95th and fifth percentile values. Both were plotted together with the average ROC time course of the nonrandomized data. The 95th and fifth percentile indicate the $5 \%$ significance criterion.

\section{Results}

\section{Behavioral effects of dlPFC deactivation}

Data were obtained over a total of 52 experimental sessions (see Materials and Methods). In each session, monkeys initially performed the task for 10-15 min, then the dlPFC region was deactivated bilaterally for $10-15$ min by pumping chilled methanol through the implanted cryoloops (Fig. $1 B$ ) while the task continued. In all sessions, we also recorded data for at least $10 \mathrm{~min}$ during the postcooling period and then contrasted the precooling and postcooling data while the lateral dlPFC was active (dlPFC+ period) with the cooling data for the period during which it was deactivated (dlPFC- period). Although the percentage of performed trials dropped during the deactivation period [ monkey A skipped more trials during the dlPFC- period compared with the dlPFC + period $(12.2$ vs $5.3 \%, p<0.001$, Wilcoxon signed rank test) and both monkeys broke fixation before peripheral stimulus presentation more often during the dlPFC - than the dlPFC + period (monkey A: 19 vs $15.6 \%, p<0.001$, Wilcoxon signed rank test; monkey B: 29.7 vs $20.4 \%, p<0.001$, Wilcoxon signed rank test)], the animals continued to perform the task.

We quantified the behavioral effects of dlPFC deactivation for all 52 experimental sessions. Table 1 shows that dlPFC deactivation increased saccadic reaction times (SRTs) with stronger effects on antisaccade than on prosaccade trials. Bilateral dlPFC deactivation also increased error rates on antisaccade trials (i.e., the monkeys made a saccade toward the stimulus more often). Error rates were higher in monkey A than monkey B. Both mon- 

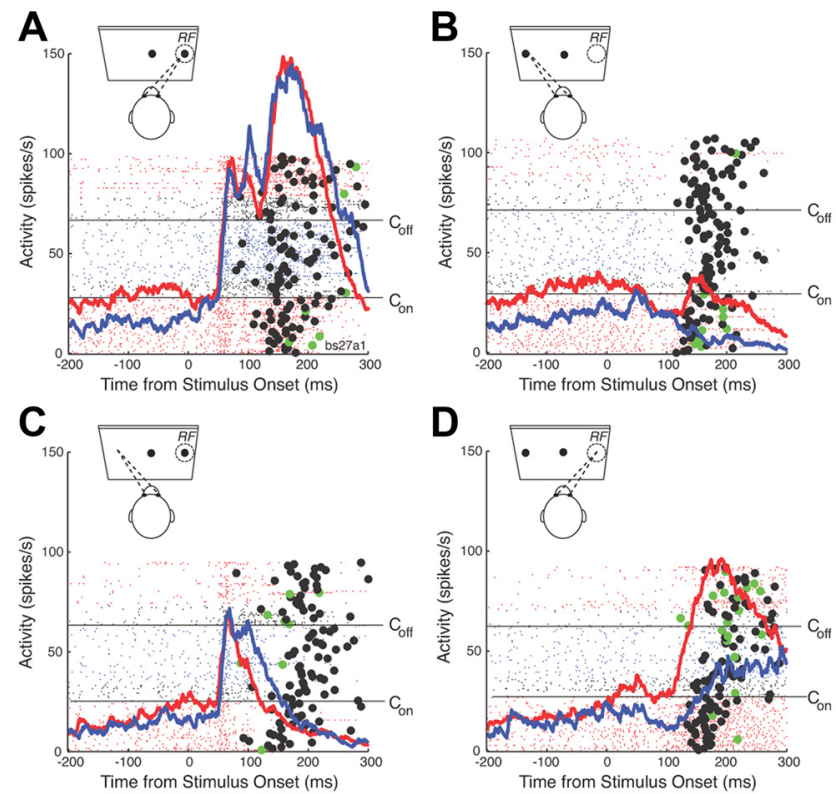

Figure 3. Single-neuron example. $A$, Activity of a single SC neuron in prosaccade trials in which the stimulus was presented in the RF of the neuron. Lines show spikes for each trial, aligned on stimulus onset. Black filled circles show the onset of the saccade. Green filled circles show the onset of errors. $C_{\text {on }}$ and $C_{\text {off }}$ indicate when cooling pumps were turned on and off. Red lines show activity when the dIPFC was not cooled (dIPFC + trials), blue lines show activity when the dIPFC was cooled bilaterally (dIPFC - trials), black lines fall into the first 4 min after $\mathrm{C}_{\text {on }}$ and $\mathrm{C}_{\text {off }}$, which were excluded as transition periods from all analysis. The mean spike density waveforms for dIPFC + (red) and dIPFC - trials (blue) are overlayed. $\boldsymbol{B}$, Same as $\boldsymbol{A}$, but for prosaccade trials in which the stimulus was presented opposite to the RF. C, $\boldsymbol{D}$, Same as $\boldsymbol{A}$ and $\boldsymbol{B}$, but for antisaccade trials.

keys made more errors in the rule-memorized than the rulevisible condition. Bilateral dlPFC deactivations also changed a number of other saccade parameters. It decreased the peak velocity of antisaccades and increased their duration.

\section{Effects of dIPFC deactivation on SC activity}

An example of the effect of bilateral dlPFC deactivation on the response of an SC saccade-related neuron is shown in Figure 3. Consistent with previous reports, the neuron had significantly higher levels of prestimulus activity on prosaccade trials than on antisaccade trials (compare Fig. $3 A, B$, red lines, $C, D$, red lines). During the cooling period (blue lines), the prestimulus activity dropped, in particular in prosaccade trials (Fig. $3 A, B$ ). In prosaccade trials in which the stimulus was presented into the RF of the neuron (Fig. 3A), the neuron had a vigorous stimulus-related response, followed by a motor burst time locked to the saccade (Fig. $3 A$, filled black circles), while the activity decayed in prosaccade trials opposite to the RF of the neuron (Fig. $3 B$ ). dlPFC deactivation had no clear effects on the stimulus- or saccade-related activity in prosaccade trials.

In antisaccade trials, the neuron had a stimulus-related response in trials in which the stimulus was presented to its RF (Fig. $3 C$ ). The activity was then suppressed before saccade onset (Fig. $3 C$, black filled circles). In trials in which the monkey made an erroneous saccade toward the stimulus (Fig. 3C, green filled circles), the neuron displayed a burst of action potentials. In dlPFC - trials (Fig. 3C, blue line), the initial stimulus-related response was the same as in $\mathrm{dlPFC}+$ trials (Fig. $3 C$, red line), but the neuron remained active longer in dlPFC - trials. In antisaccade trials in which the monkey had to generate a saccade in the RF of the neuron (Fig. 3D), the neuron displayed a motor burst
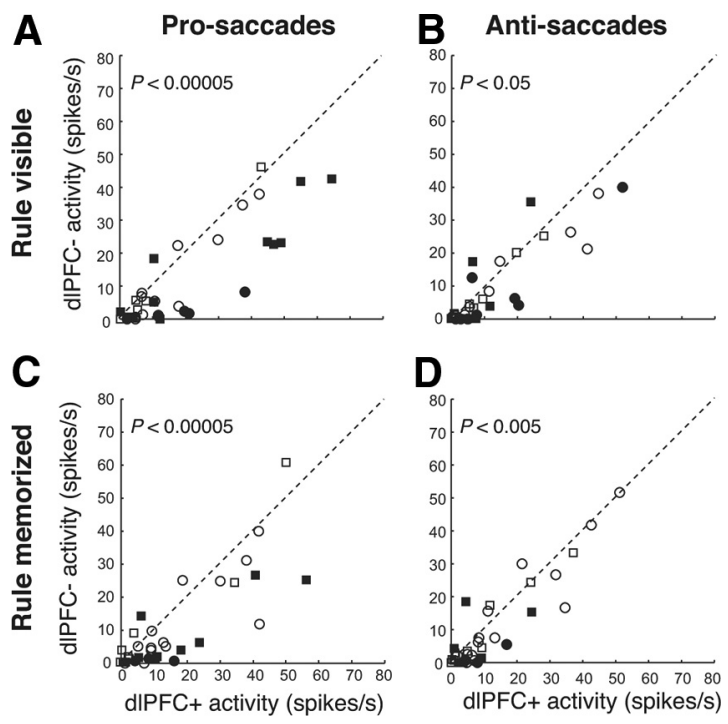

Figure 4. Effects of dIPFC deactivation on prestimulus activity in the SC. $A$, The mean activity of individual neurons in the period from $50 \mathrm{~ms}$ before to $50 \mathrm{~ms}$ after stimulus presentation in $\mathrm{dIPFC}+$ trials is plotted against the mean activity in $\mathrm{dIPFC}-$ trials in the rule-visible condition in prosaccade trials. Circles and squares indicate neurons recorded from monkeys $A$ and $B$, respectively. Filled symbols indicate neurons with significant differences (Wilcoxon rank sum test, $p<0.05$ ). The dashed line is the unity line (slope, 1). $\boldsymbol{B}$, Same as in $\boldsymbol{A}$, but in antisaccade trials in the rule-memorized condition. $\boldsymbol{C}, \boldsymbol{D}$, Same as in $\boldsymbol{A}$ and $\boldsymbol{B}$, but in the rule-memorized condition.

for the saccade, which was reduced and delayed in dlPFC - trials (Fig. 3D, blue line).

\section{Prestimulus activity}

Next, we examined the effects of bilateral dlPFC deactivation on the activity immediately before the arrival of the visual signal in the SC in our sample of 34 SC neurons. We measured the level of prestimulus activity in the period from $50 \mathrm{~ms}$ before to $50 \mathrm{~ms}$ after stimulus presentation because SC neurons have visual onset responses $>50 \mathrm{~ms}$ (Everling et al., 1999). Therefore, the activity in our analysis period reflected the activation level before stimulus presentation and was not influenced by the arrival of the visual signal. Consistent with previous reports (Everling et al., 1999), SC neurons displayed higher levels of prestimulus activity in the period from $50 \mathrm{~ms}$ before to $50 \mathrm{~ms}$ after stimulus onset in prosaccade trials $(19.2 \pm 3.2$ spikes/s $)$ than in antisaccade trials $(12.1 \pm 2.3$ spikes/s $)(p<0.005$, Wilcoxon signed rank test $)$ in the rule-visible condition. Moreover, we found that these differences were also present in the rule-memorized condition in which the FP had the same color in prosaccade and antisaccade trials $(16.1 \pm 2.8$ vs $12.1 \pm 2.3$ spikes/s, respectively; $p<0.05$, Wilcoxon signed rank test). The level of prestimulus activity dropped significantly ( $p<0.001$, Wilcoxon signed rank test) during the dlPFC - period in prosaccade trials [from $19.2 \pm 3.2$ to $11.8 \pm 3.2 \mathrm{spikes} / \mathrm{s}$ in the rule-visible condition (Fig. $4 \mathrm{~A}$ ); from $16.1 \pm 2.8$ to $10.3 \pm 2.7$ spikes/s in the rule-memorized condition (Fig. $4 B$ )]. We also observed significant decreases in prestimulus activity in dlPFC - compared with dlPFC + trials in the rulevisible condition in antisaccade trials $(10.2 \pm 2.3$ vs $12.1 \pm 2.3$ spikes/s; $p<0.05$, Wilcoxon signed rank test) (Fig. $4 C$ ) and in the rule-memorized condition $(8.8 \pm 2.4$ vs $11.6 \pm 2.4$ spikes/s; $p<$ 0.005 , Wilcoxon signed rank test) (Fig. $4 D$ ). As a consequence, the prestimulus activity was no longer different between prosaccade and antisaccade trials in the rule-visible or rule-memorized 

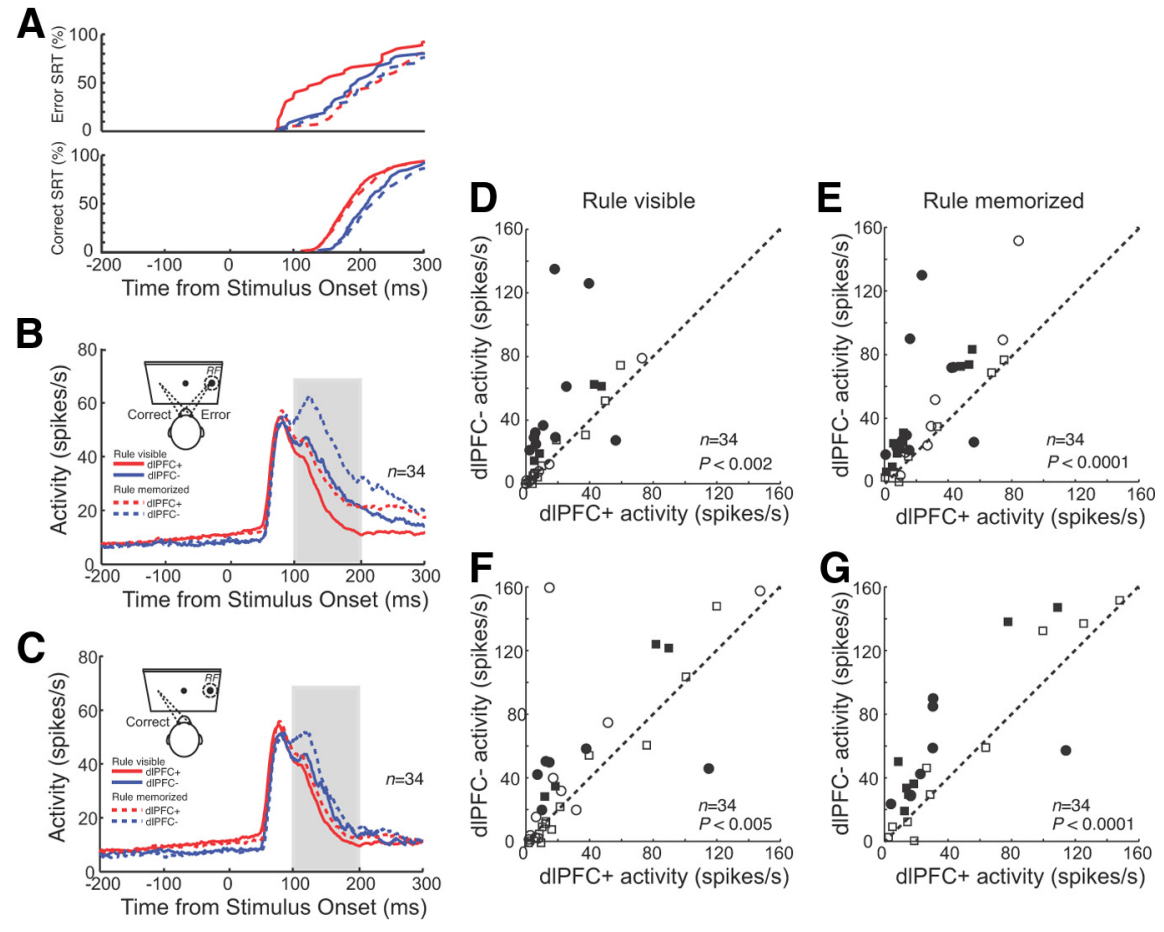

Figure 5. Effects of dIPFC deactivation on stimulus-related activity in the SC in antisaccade trials. $A$, Cumulative distributions of correct saccadic reaction times and error saccadic reaction times in $\mathrm{IIPFC}^{+}$trials (red lines) and $\mathrm{dIPFC}$ - trials (blue lines) in the rule-visible condition (solid lines) and rule-memorized condition (dashed lines). $\boldsymbol{B}$, Mean spike density in dIPFC ${ }^{+}$trials (red lines) and dIPFC - trials (blue lines) in the rule-visible condition (solid lines) and rule-memorized condition (dashed lines) for combined correct and error trials. In this and subsequent figures, display icons show the response filled (dashed circle, RF) on the right, though the actual side varied between cells. $\boldsymbol{C}$, Same as in $\boldsymbol{B}$, but only for correct trials. $\boldsymbol{D}$, The mean activity of individual neurons in the period $100-200$ ms after stimulus presentation ( $\boldsymbol{B}$, shaded region) in dIPFC + trials is plotted against the mean activity in dIPFC trials in the rule-visible condition. Circles and squares indicate neurons recorded from monkeys $A$ and $B$, respectively. Filled symbols indicate neurons with significant differences (Wilcoxon rank sum test, $p<0.05$ ). The dashed line is the unity line (slope, 1). $\boldsymbol{E}$, Same as in $\boldsymbol{D}$, but in the rule-memorized condition. $\boldsymbol{F}, \boldsymbol{G}$, Same as in $\boldsymbol{D}$ and $\boldsymbol{E}$, but only for correct trials ( $\boldsymbol{C}$.
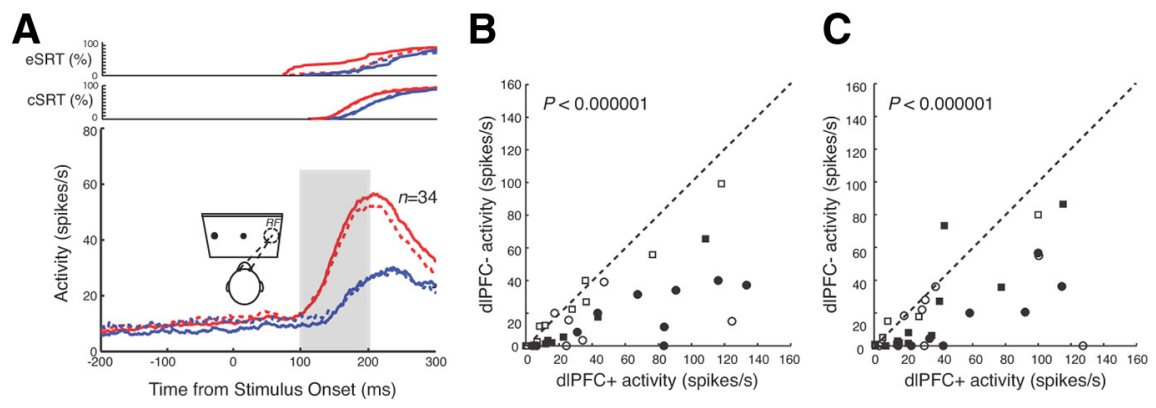

Figure 6. Effects of dIPFC deactivation on saccade-related activity in the SC in antisaccade trials. $A$, Mean spike density in $\mathrm{dIPFC}^{+}$trials (red lines) and dIPFC - trials (blue lines) in the rule-visible condition (solid lines) and rule-memorized condition (dashed lines). Cumulative distributions of correct SRTs (CSRTs) and error SRTs (eSRT) are shown in the top panels. $\boldsymbol{B}$, The mean activity of individual neurons in the period $100-200 \mathrm{~ms}$ after stimulus presentation ( $A$, shaded region) in dIPFC + trials is plotted against the mean activity in $\mathrm{dIPFC}-$ trials in the rule-visible condition. Circles and squares indicate neurons recorded from monkeys $A$ and $B$, respectively. Filled symbols indicate neurons with significant differences (Wilcoxon rank sum test, $p<0.05$ ). The dashed line is the unity line (slope, 1). $\boldsymbol{C}$, Same as in $\boldsymbol{B}$, but in the rule-memorized condition.

condition during dlPFC deactivation $(p>0.05$, Wilcoxon signed rank test).

\section{Stimulus-related activity}

Similar to the single neuron presented in Figure 3, the population of $\mathrm{SC}$ neurons also responded to the presentation of the stimulus in their RFs in antisaccade trials (Fig. 5B). The initial response did not vary between dlPFC + and dlPFC - trials. However, the ac- tivity of the neurons remained higher in dlPFC - trials. We quantified these differences in the period $100-200 \mathrm{~ms}$ after stimulus onset. In the rule-visible condition, the mean activity was $17.7 \pm 3.5$ spikes/s in dlPFC - trials and $29.7 \pm 3.5$ spikes/s in dlPFC - trials $(p<0.002$, Wilcoxon signed rank test). Significant differences ( $p<0.05$, Wilcoxon rank sum test) were obtained in $38 \%$ (13 of 34 ) of the neurons (Fig. 5D). Differences between dlPFC+ and dlPFC - trials were even stronger in the rule-memorized condition (Fig. 5E). Here, $53 \%$ (18 of 34 ) of neurons displayed significant differences, with $26.9 \pm 5.2 \mathrm{spikes} / \mathrm{s}$ in $\mathrm{dlPFC}+$ trials and $42.5 \pm 4.2$ spikes/s on dlPFC - trials ( $p<$ 0.0001 , Wilcoxon rank sum test). These differences may have been simply the result of more erroneous saccades and therefore saccade-related bursts in dIPFC - trials. To rule out this simple explanation, we repeated the same analysis for correct trials only (Fig. 5C). This analysis showed that the differences between dlPFC + and dlPFC - trials were still present when error trials were excluded from the analysis [rule-visible condition: $15.9 \pm 3.4$ vs $22.5 \pm 3.4$ spikes/s, $p<$ 0.005 , Wilcoxon signed rank test (Fig. $5 F)$; rule-memorized condition: $19.3 \pm$ 3.7 vs $29.4 \pm 3.7$ spikes/s, $p<0.0001$, Wilcoxon signed rank test (Fig. 5G)].

\section{Saccade-related activity}

To test the effects of dlPFC deactivation on saccade-related activity in the SC, we examined the population activity in antisaccade trials when the stimulus was presented opposite to the RF of the neurons (i.e., saccades were directed into the RF) (Fig. 6A). Again, we quantified neural activity in the period $100-200 \mathrm{~ms}$ after stimulus onset. In the rule-visible condition, SC neurons were more active in the dlPFC + condition $(45.3 \pm 7.0$ spikes/s $)$ than in the dlPFC - condition (18.9 \pm 7.0 spikes/s). These differences were significant for the population $(p<0.000001$, Wilcoxon signed rank test) and for $47 \%$ (16 of 34) of SC neurons ( $p<0.05$, Wilcoxon rank sum test) (Fig. 6 B). Similarly, in the rule-memorized condition, neurons were also more active in the dlPFC+ condition $(41.3 \pm 6.5$ spikes/s) than in the dlPFC - condition $(19.5 \pm 6.5$ spikes/s $)(p<0.000001$, Wilcoxon signed rank test). Here, $53 \%$ (18 of 34 ) of the neurons had significant differences in activity $(p<0.05$, Wilcoxon rank sum test) (Fig. 6C). These differences were also present when only correct trials were included in the analysis $(p<0.0001$, Wilcoxon signed rank test). However, it should be noted that the differences in this analysis are more difficult to interpret, because dIPFC deactivation also reduced the velocity, increased the duration, 
and, likely most relevant for this analysis, changed the gain for antisaccades (Table 1).

\section{Time course of dIPFC deactivation on population activity in the SC}

To perform a more principled analysis of the time courses of the effects of dlPFC deactivation on SC activity on antisaccade trials, we performed an ROC analysis on the convolved activity in $10 \mathrm{~ms}$ time bins, shifted by $1 \mathrm{~ms}$ (Fig. 7). To test whether these ROC values were significantly different from chance, we also conducted bootstrap analyses (see Materials and Methods). The analysis confirmed significant differences in neural activity starting at $100 \mathrm{~ms}$ following stimulus onset between dlPFC - and dlPFC + trials in which the stimulus was presented in the RF of the neurons.

\section{Error trials}

To directly test whether errors in antisaccade trials during dlPFC deactivation are the result of an increased motor preparation during the prestimulus period or of a failure to suppress the stimulus-related response, we compared correct trials and error trials (Fig. 8). We performed this analysis for 16 neurons for which we had obtained at least four errors in antisaccade trials during the deactivation period. Data from the rule-visible and rule-memorized conditions were combined for this analysis. In contrast to our previous study that compared correct antisaccades and errors in monkeys with an active dlPFC in a gap saccade task (Everling et al., 1998), we did not find any differences between correct and error trials during the prestimulus period in SC neurons (Fig. $8 \mathrm{~A}$ ). It should be noted that the errors in the gap saccade task were mainly short-latency express saccades (Everling et al., 1998), whereas the errors during dlPFC deactivation had longer reaction times (Fig. 5A). Differences between correct and error trials emerged following the initial stimulus-related response, when the activity was suppressed in correct trials but continued to increase in error trials to culminate in a motor burst (Fig. $8 A$, right). Note that although the activity was suppressed in correct dlPFC - trials (Fig. 8A, solid blue line), this suppression was faster in correct dlPFC+ trials (Fig. 8A, red line). When tested with an ROC analysis with a $10 \mathrm{~ms}$ sliding window (Fig. $8 B$ ), differences between correct antisaccades (solid blue line) and error trials (dashed blue line) in Figure $8 \mathrm{~A}$ became statistically significant $103 \mathrm{~ms}$ following stimulus onset. Relative to saccade onset, significant differences emerged $90 \mathrm{~ms}$ before their start. The differences between correct dlPFC + and correct dlPFC - trials were also significant following stimulus presentation in the period from 136 to $182 \mathrm{~ms}$ after stimulus onset and in the $100 \mathrm{~ms}$ preceding the saccade (Fig. 8C). These findings demonstrate that in monkeys with a bilaterally deactivated dlPFC errors occur on antisaccade trials when the activity is not suppressed at $\sim 100 \mathrm{~ms}$ following stim-
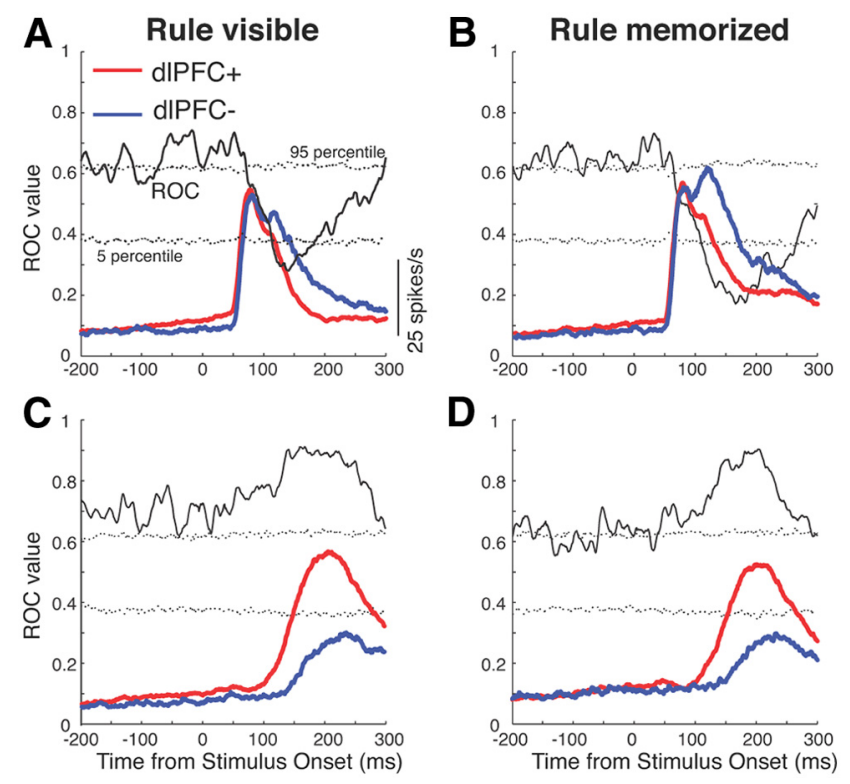

Figure 7. Time course of dIPFC deactivation effects. $A$, Mean spike density in $\mathrm{dIPFC}+$ trials (red lines) and dIPFC - trials (blue lines) in the rule-visible condition for antisaccade trials in which the stimulus was presented into the RF of the neurons. Time courses of average population ROC values for the comparison of $\mathrm{dIPFC}+$ with dIPFC - trials are overlayed. Dotted lines represent percentile values obtained from a bootstrap analysis. Periods in which the solid lines lay above or below the dotted lines indicate periods with differences $(p<0.05)$. $\boldsymbol{B}$, Same as in $\boldsymbol{A}$, but for the rule-memorized condition. $\boldsymbol{C}, \boldsymbol{D}$, Same as $\boldsymbol{A}$ and $\boldsymbol{B}$, but for antisaccade trials in which the saccade was directed toward the RF of the neurons.

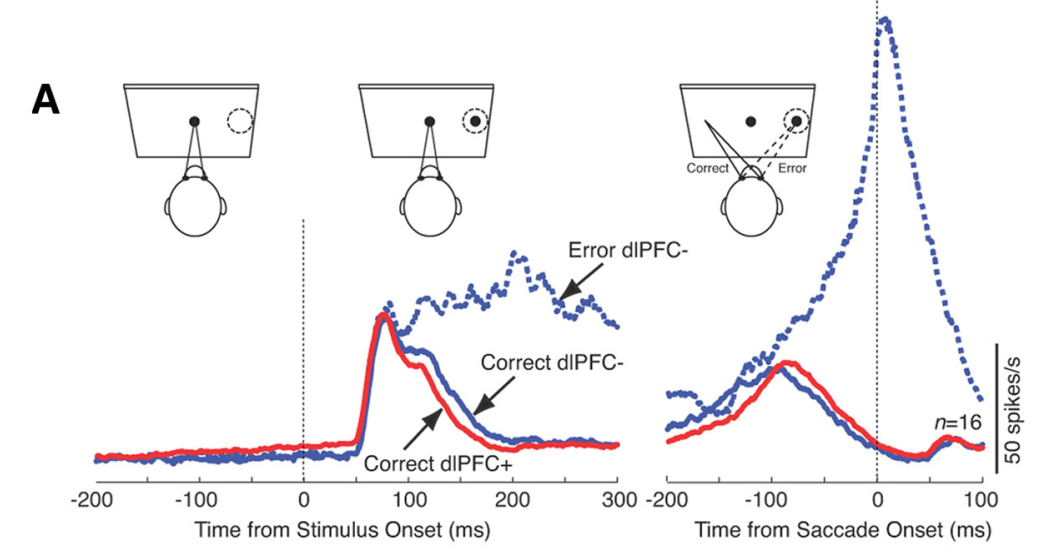

B Correct dIPFC- vs. Error dIPFC-
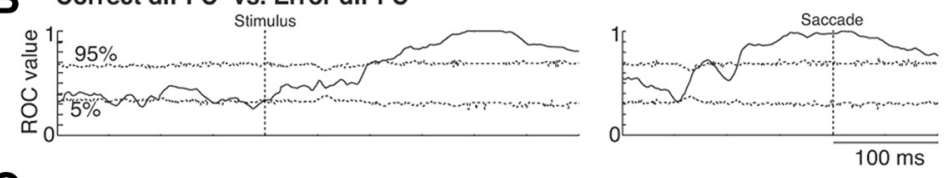

C Correct dIPFC+ vs. Correct dIPFC-
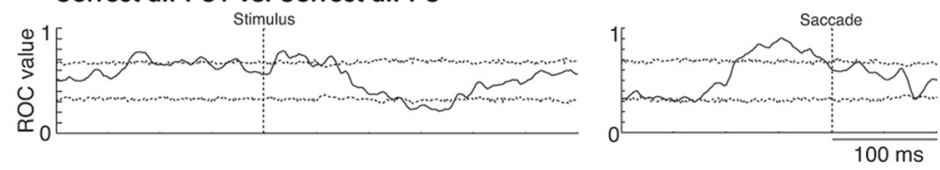

Figure 8. Population activity of SC neurons in correct and error trials. $A$, Mean spike density in correct dIPFC + trials (red lines), correct dIPFC - trials (solid blue lines), and error trials (dashed blue lines). Left, Activity aligned on stimulus onset; right, activity aligned on saccade onset. $\boldsymbol{B}$, Time course of average population ROC values for the comparison of correct $\mathrm{dIPFC}$ - with error $\mathrm{dIPFC}$ - trials (solid lines) aligned on stimulus onset (left) and saccade onset (right). Dotted lines represent percentile values obtained from a bootstrap analysis. Periods in which the solid lines lay above or below the dotted lines indicate periods with significant differences $(p<0.05)$. C, Same as in $\boldsymbol{B}$, but for the comparison of correct dIPFC + and correct dIPFC - trials. 
A Cooled ipsilateral to RF

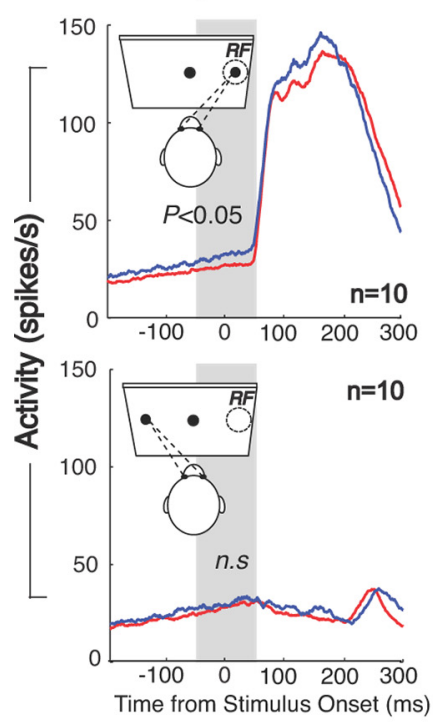

B Cooled contralateral to RF
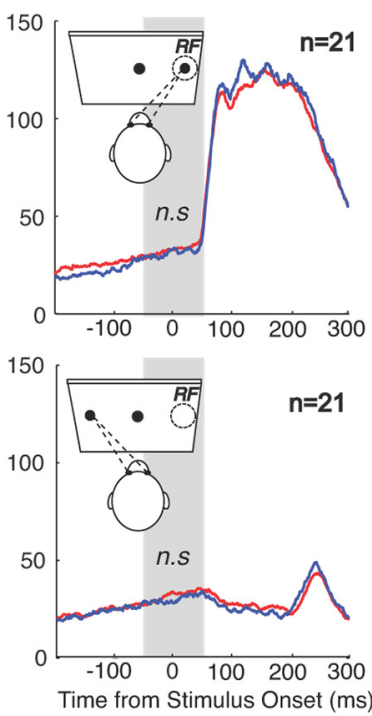

C Cooled ipsilateral to RF

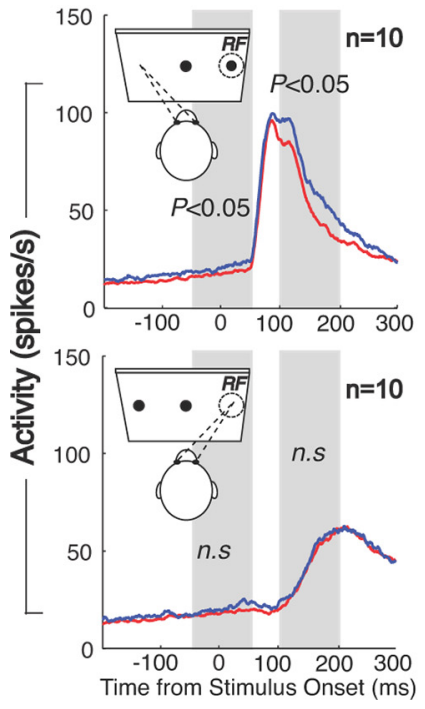

D Cooled contralateral to RF
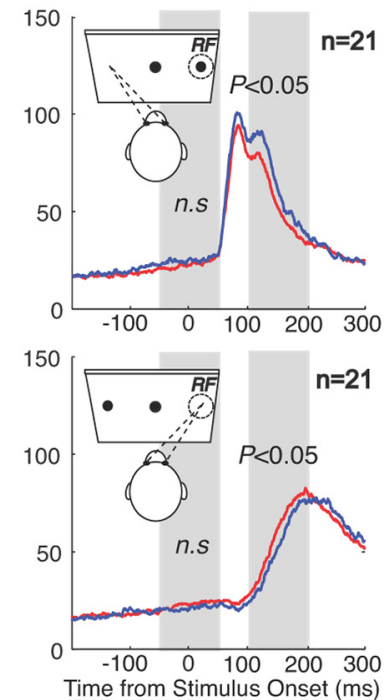

Figure 9. Effects of unilateral cooling on behavior and SC single-unit activity. $A$, SRTs and error rates (top) and mean spike density in $\mathrm{dIPFC}^{+}$trials (red lines) and dIPFC - trials (blue lines) in the rule-visible condition in prosaccades when the dIPFC contralateral to the RF of the neurons was deactivated. $\boldsymbol{B}$, Same as in $\boldsymbol{A}$, but for prosaccade trials when the dIPFC ipsilateral to the RF was deactivated. $\boldsymbol{C}, \boldsymbol{D}$, Same as in $\boldsymbol{A}$ and $\boldsymbol{B}$, but for antisaccade trials.

ulus onset. The data also demonstrate that neural activity in the SC even differs between correct dlPFC+ trials and correct dlPFC - trials.

\section{Unilateral dIPFC deactivation}

Though we have focused on the effects of bilateral dlPFC deactivation, we also conducted some experiments with unilateral dIPFC deactivations in the rule-visible condition (Fig. 9). As in the bilateral deactivation experiment, unilateral deactivations were associated with prolonged stimulus-related activity in antisaccade trials in the SC ipsilateral (Fig. 9C) and contralateral (Fig. $9 D$ ) to the deactivated hemisphere. Moreover, activity before antisaccades was lower for saccades directed contralateral to the deactivated hemisphere (Fig. 9D). In addition, unilateral deactivation led to strong lateralized effects, with higher levels of pre- stimulus activity in the SC contralateral to the deactivated hemisphere (Fig. 9A,C). These findings suggest that unilateral dIPFC deactivation led to an imbalance in activity in the two SCs, with a decrease in activity in the ipsilateral SC and an increase in activity in the contralateral SC. This is consistent with the observation that unilateral injections of muscimol in the ventral bank of the dlPFC lead to more antisaccade errors when the stimulus is presented ipsilateral to the injection (Condy et al., 2007). Not surprising, such an imbalance was not observed with bilateral PFC deactivation.

\section{Discussion}

An influential hypothesis of dlPFC function has emphasized its role in biasing the activity in sensory and motor areas depending on behavioral rules and goals (Miller and Cohen, 2001). Although several previous studies have described the effects of dIPFC deactivation on neural activity in the thalamus (Fuster and Alexander, 1973) and in the parietal (Chafee and Goldman-Rakic, 2000) and inferotemporal cortex (Fuster et al., 1985) in delayed response and delayed match-to-sample tasks, it remained unknown how the dIPFC modulates neural activity to establish mappings between inputs and outputs depending on different rules. Here, we investigated the effects of dlPFC deactivation by cortical cooling on neural activity in the SC using two simple oculomotor tasks with different stimulus-response (SR) mapping rules (Everling and Fischer, 1998; Munoz and Everling, 2004). In prosaccade trials, monkeys had to follow a congruent SR mapping rule by looking toward a flashed stimulus, whereas antisaccade trials required an incompatible SR mapping rule by looking away from the stimulus in the opposite direction. We found that dIPFC deactivation eliminated the differences in neural activity between the two SR mapping rules during the prestimulus period, impaired the suppression of the stimulus-driven response, and delayed the generation of the motor response in antisaccade trials. These findings support the hypothesis that the dlPFC plays an important role in arbitrary SR mappings (Miller and Cohen, 2001; Fusi et al., 2007; Sakai, 2008) and reveal a neural mechanism by which the dlPFC exerts taskdependent control on neural activity in the SC.

Neural correlates of behavioral rules and categories have been found in many studies of PFC function (Hoshi et al., 1998; Rainer et al., 1998; White and Wise, 1999; Asaad et al., 2000). Recently, Buckley et al. (2009) tested the effects of circumscribed PFC lesions on separable task components in a monkey analog of the Wisconsin Card Sorting Test. Animals with lesions restricted to the principal sulcus made more errors after a brief interruption of the task. This is consistent with our finding that principal sulcus deactivation was associated with more errors in the rulememorized condition compared with the rule-visible condition. Both findings support a role of the dlPFC in working memory for rules.

Indeed, task-related differences between prosaccade and antisaccade trials during the prestimulus period have been described in PFC neurons (Funahashi et al., 1993; Everling and DeSouza, 2005; Johnston and Everling, 2006a; Johnston et al., 2007, 2009). Moreover, a subset of dlPFC neurons sends these task-selective signals directly to the SC (Johnston and Everling, 2006b). The low-frequency activity in the SC well in advance of the saccade itself has been termed "prelude" (Glimcher and Sparks, 1992) or "buildup" (Munoz and Wurtz, 1995) and has been shown to be associated with motor preparation (Dorris et al., 1997; Everling et al., 1999), target probability (Basso and Wurtz, 1998; Dorris and Munoz, 1998), covert shifts of attention (Kustov and Robinson, 
1996; Ignashchenkova et al., 2004), target selection (Horwitz and Newsome, 2001; McPeek and Keller, 2002), and choice (Thevarajah et al., 2009).

Consistent with a previous study (Everling et al., 1999), we found that saccade-related SC neurons display higher levels of prestimulus activity in prosaccade trials than in antisaccade trials during noncooling trials. Moreover, we showed here that SC neurons display these differences even when the monkeys had to briefly memorize the instruction during the delay period. These task-selective differences in preparatory activity have been interpreted to reflect reduced motor preparation in antisaccade trials. Munoz and Everling (2004) hypothesized that the correct performance of antisaccades requires the suppression of neural activity in the SC before the stimulus appears to prevent the stimulusdriven activity to pass the saccade threshold and trigger a shortlatency express saccade. The authors hypothesized that prefrontal lesions would lead to more response errors in the antisaccade task by increasing the prestimulus activity in the SC (Munoz and Everling, 2004). Here we demonstrate that this is not the case. Bilateral deactivation of area 46 in the dlPFC reduced the levels of prestimulus activity in the SC and eliminated the differences in activity between prosaccade and antisaccade trials. Considering that the level of prestimulus activity of SC neurons is negatively correlated with saccadic reaction times (Dorris et al., 1997; Everling et al., 1999), this finding can explain the increased reaction times of prosaccade and antisaccade during dlPFC deactivation and in patients with prefrontal lesions. In a more general framework, a reduced motor preparation may underlie hypokinesia (i.e., delay in initiating a response) in these patients. While the reduction in prestimulus activity can explain the longer reaction times, it cannot account for the increased error rates during dlPFC deactivation. In fact, a direct comparison of correct and error trials during dlPFC deactivation did not show any differences in prestimulus activity.

Our data show that dlPFC deactivation impaired the suppression of the stimulus-related response in SC neurons. While the amplitude of the initial visual response did not differ between cooling and noncooling trials, SC neurons remained active longer in cooling trials than in noncooling trials. The comparison of correct trials and error trials demonstrated that the activity started to be suppressed $\sim 100 \mathrm{~ms}$ following stimulus onset on correct trials, whereas the activity continued to increase in error trials. An impairment to efficiently suppress the unwanted stimulus-driven signal during dlPFC deactivation may be the neural correlate for the known role of the lateral PFC in inhibiting "prepotent" (i.e., dominant) response tendencies (Diamond and Goldman-Rakic, 1989). The finding is also reminiscent of the increased amplitude of auditory evoked potentials in patients with prefrontal lesions (Knight et al., 1989; Alho et al., 1994) and may underlie the inability of patients with prefrontal damage to filter out irrelevant stimuli (Fuster, 2008).

Antidromic stimulation studies have shown that the dlPFC sends a mixture of preparatory, stimulus-related, and saccaderelated signals directly to the superior colliculus (Johnston and Everling, 2006b, 2009). In the antisaccade task, the most prevalent task-selective signals of corticotectal dlPFC neurons are higher levels of prestimulus activity and an enhanced contralateral stimulus-related activity for antisaccades compared with prosaccades (Johnston and Everling, 2006b). This activity pattern, which might be shaped by the microcircuitry in the dlPFC (Johnston et al., 2009), has been interpreted as a signal that suppresses the activity in antisaccade trials. Our finding of a decrease in prestimulus activity and prolonged stimulus-related activity during dlPFC deactivation may suggest that the dlPFC has excitatory effects during the preparatory period and inhibitory effects on the SC during the stimulus period.

Although the direct projections from layer $\mathrm{V}$ of the dlPFC to the intermediate layers of the superior colliculus (Goldman and Nauta, 1976; Leichnetz et al., 1981; Fries, 1984) are excitatory, it is unknown whether these axons synapse directly in saccade-related neurons or in inhibitory interneurons that mediate local and long-range inhibition in the SC (Sooksawate et al., 2011). Corticocortical neurons in primates are also excitatory and mainly form synapses with other excitatory neurons (White, 1989; Somogyi et al., 1998), although there are projections to inhibitory neurons that have been proposed to improve response selectivity in behavioral tasks (Medalla and Barbas, 2009). Moreover, although it is tempting to speculate that the effects of dlPFC deactivation on SC activity result from elimination of direct projections from the dlPFC to the SC, prefrontal cooling is known to alter thalamic activity (Fuster and Alexander, 1973), and the dIPFC could also influence the activity in the SC indirectly through projections via the frontal eye fields, supplementary eye fields, and basal ganglia, which also carry task-related signals for prosaccades and antisaccades (Schlag-Rey et al., 1997; Everling and Munoz, 2000; Ford and Everling, 2009; Watanabe and Munoz, 2009; Yoshida and Tanaka, 2009). It is therefore conceivable that the dlPFC has both inhibitory and excitatory influences on the SC, depending on task requirements.

Alternatively, the deficit in inhibiting the stimulus-driven response may be directly related to the impairment in generating the motor command for the antisaccade. According to the biased competition model of Desimone and Duncan (1995), inhibition occurs because of local competition among conflicting representations. In the antisaccade task, this could be viewed as a competition between the representation of the motor programs for the stimulus-driven prosaccade and the instructed antisaccade. The contribution of the dlPFC to the performance of antisaccades could be a biasing of the motor command for antisaccades. In this case, a removal of this bias signal would result in prolonged stimulus-driven responses and response errors, and in delayed motor responses. Therefore, deficits in generating the motor command for the antisaccade could be directly responsible for the prolonged stimulus-related response during dlPFC deactivation.

In summary, our results demonstrate a neural mechanism by which the dlPFC exerts task-dependent control of neural activity in the SC. The reduced preparatory activity, impaired suppression of sensory-driven activity, and delay in generating the motor burst for antisaccades during bilateral dlPFC deactivation can explain the robust behavioral deficits of patients with prefrontal damage or dysfunction in the antisaccade task (Everling and Fischer, 1998).

\section{References}

Adey WR (1974) Biophysical and metabolic bases of cooling effects on cortical membrane potentials in the cat. Exp Neurol 42:113-140.

Alexander GE, Fuster JM (1973) Effects of cooling prefrontal cortex on cell firing in the nucleus medialis dorsalis. Brain Res 61:93-105.

Alho K, Woods DL, Algazi A, Knight RT, Näätänen R (1994) Lesions of frontal cortex diminish the auditory mismatch negativity. Electroencephalogr Clin Neurophysiol 91:353-362.

Asaad WF, Rainer G, Miller EK (2000) Task-specific neural activity in the primate prefrontal cortex. J Neurophysiol 84:451-459.

Basso MA, Wurtz RH (1998) Modulation of neuronal activity in superior colliculus by changes in target probability. J Neurosci 18:7519-7534.

Bauer RH, Fuster JM (1976) Delayed-matching and delayed-response defi- 
cit from cooling dorsolateral prefrontal cortex in monkeys. J Comp Physiol Psychol 90:293-302.

Broerse A, Crawford TJ, den Boer JA (2001) Parsing cognition in schizophrenia using saccadic eye movements: a selective overview. Neuropsychologia 39:742-756.

Brown MR, Vilis T, Everling S (2008) Isolation of saccade inhibition processes: rapid event-related fMRI of saccades and nogo trials. Neuroimage 39:793-804.

Buckley MJ, Mansouri FA, Hoda H, Mahboubi M, Browning PG, Kwok SC, Phillips A, Tanaka K (2009) Dissociable components of ruleguided behavior depend on distinct medial and prefrontal regions. Science 325:52-58.

Chafee MV, Goldman-Rakic PS (2000) Inactivation of parietal and prefrontal cortex reveals interdependence of neural activity during memoryguided saccades. J Neurophysiol 83:1550-1566.

Condy C, Wattiez N, Rivaud-Péchoux S, Tremblay L, Gaymard B (2007) Antisaccade deficit after inactivation of the principal sulcus in monkeys. Cereb Cortex 17:221-229.

Desimone R, Duncan J (1995) Neural mechanisms of selective visual attention. Annu Rev Neurosci 18:193-222.

DeSouza JF, Menon RS, Everling S (2003) Preparatory set associated with pro-saccades and anti-saccades in humans investigated with event-related FMRI. J Neurophysiol 89:1016-1023.

Diamond A, Goldman-Rakic PS (1989) Comparison of human infants and rhesus monkeys on Piaget's AB task: evidence for dependence on dorsolateral prefrontal cortex. Exp Brain Res 74:24-40.

Dorris MC, Munoz DP (1998) Saccadic probability influences motor preparation signals and time to saccadic initiation. J Neurosci 18:7015-7026.

Dorris MC, Paré M, Munoz DP (1997) Neuronal activity in monkey superior colliculus related to the initiation of saccadic eye movements. J Neurosci 17:8566-8579.

Dyckman KA, Camchong J, Clementz BA, McDowell JE (2007) An effect of context on saccade-related behavior and brain activity. Neuroimage $36: 774-784$

Everling S, DeSouza JF (2005) Rule-dependent activity for prosaccades and antisaccades in the primate prefrontal cortex. J Cogn Neurosci 17:1483-1496.

Everling S, Fischer B (1998) The antisaccade: a review of basic research and clinical studies. Neuropsychologia 36:885-899.

Everling S, Munoz DP (2000) Neuronal correlates for preparatory set associated with pro-saccades and anti-saccades in the primate frontal eye field. J Neurosci 20:387-400.

Everling S, Dorris MC, Munoz DP (1998) Reflex suppression in the antisaccade task is dependent on prestimulus neural processes. J Neurophysiol 80:1584-1589.

Everling S, Dorris MC, Klein RM, Munoz DP (1999) Role of primate superior colliculus in preparation and execution of anti-saccades and prosaccades. J Neurosci 19:2740-2754.

Ford KA, Everling S (2009) Neural activity in primate caudate nucleus associated with pro- and anti-saccades. J Neurophysiol 102:2334-2341.

Ford KA, Goltz HC, Brown MR, Everling S (2005) Neural processes associated with antisaccade task performance investigated with event-related FMRI. J Neurophysiol 94:429-440.

Fries W (1984) Cortical projections to the superior colliculus in the macaque monkey: a retrograde study using horseradish peroxidase. J Comp Neurol 230:55-76.

Fukushima J, Fukushima K, Chiba T, Tanaka S, Yamashita I, Kato M (1988) Disturbances of voluntary control of saccadic eye movements in schizophrenic patients. Biol Psychiatry 23:670-677.

Fukushima J, Fukushima K, Morita N, Yamashita I (1990) Further analysis of the control of voluntary saccadic eye movements in schizophrenic patients. Biol Psychiatry 28:943-958.

Funahashi S, Chafee MV, Goldman-Rakic PS (1993) Prefrontal neuronal activity in rhesus monkeys performing a delayed anti-saccade task. Nature 365:753-756.

Fusi S, Asaad WF, Miller EK, Wang XJ (2007) A neural circuit model of flexible sensorimotor mapping: learning and forgetting on multiple timescales. Neuron 54:319-333.

Fuster JM (2008) The prefrontal cortex. London: Elsevier.

Fuster JM, Alexander GE (1970) Delayed response deficit by cryogenic depression of frontal cortex. Brain Res 20:85-90.

Fuster JM, Alexander GE (1973) Firing changes in cells of the nucleus me- dialis dorsalis associated with delayed response behavior. Brain Res 61:79-91.

Fuster JM, Bauer RH, Jervey JP (1985) Functional interactions between inferotemporal and prefrontal cortex in a cognitive task. Brain Res 330:299-307.

Glimcher PW, Sparks DL (1992) Movement selection in advance of action in the superior colliculus. Nature 355:542-545.

Goldman PS, Nauta WJ (1976) Autoradiographic demonstration of a projection from prefrontal association cortex to the superior colliculus in the rhesus monkey. Brain Res 116:145-149.

Guitton D, Buchtel HA, Douglas RM (1985) Frontal lobe lesions in man cause difficulties in suppressing reflexive glances and in generating goaldirected saccades. Exp Brain Res 58:455-472.

Hanes DP, Schall JD (1996) Neural control of voluntary movement initiation. Science 274:427-430.

Horwitz GD, Newsome WT (2001) Target selection for saccadic eye movements: prelude activity in the superior colliculus during a directiondiscrimination task. J Neurophysiol 86:2543-2558.

Hoshi E, Shima K, Tanji J (1998) Task-dependent selectivity of movementrelated neuronal activity in the primate prefrontal cortex. J Neurophysiol 80:3392-3397.

Hutton SB, Ettinger U (2006) The antisaccade task as a research tool in psychopathology: a critical review. Psychophysiology 43:302-313.

Ignashchenkova A, Dicke PW, Haarmeier T, Thier P (2004) Neuronspecific contribution of the superior colliculus to overt and covert shifts of attention. Nat Neurosci 7:56-64.

Johnston K, Everling S (2006a) Neural activity in monkey prefrontal cortex is modulated by task context and behavioral instruction during delayedmatch-to-sample and conditional prosaccade-antisaccade tasks. J Cogn Neurosci 18:749-765.

Johnston K, Everling S (2006b) Monkey dorsolateral prefrontal cortex sends task-selective signals directly to the superior colliculus. J Neurosci 26:12471-12478.

Johnston K, Everling S (2009) Task-relevant output signals are sent from monkey dorsolateral prefrontal cortex to the superior colliculus during a visuospatial working memory task. J Cogn Neurosci 21:1023-1038.

Johnston K, Levin HM, Koval MJ, Everling S (2007) Top-down controlsignal dynamics in anterior cingulate and prefrontal cortex neurons following task switching. Neuron 53:453-462.

Johnston K, DeSouza JF, Everling S (2009) Monkey prefrontal cortical pyramidal and putative interneurons exhibit differential patterns of activity between prosaccade and antisaccade tasks. J Neurosci 29:5516-5524.

Kinsbourne M (1977) Hemi-neglect and hemisphere rivalry. Adv Neurol $18: 41-49$

Knight RT, Scabini D, Woods DL (1989) Prefrontal cortex gating of auditory transmission in humans. Brain Res 504:338-342.

Kustov AA, Robinson DL (1996) Shared neural control of attentional shifts and eye movements. Nature 384:74-77.

Leichnetz GR, Spencer RF, Hardy SG, Astruc J (1981) The prefrontal corticotectal projection in the monkey; an anterograde and retrograde horseradish peroxidase study. Neuroscience 6:1023-1041.

Lomber SG, Payne BR, Horel JA (1999) The cryoloop: an adaptable reversible cooling deactivation method for behavioral or electrophysiological assessment of neural function. J Neurosci Methods 86:179-194.

McDowell JE, Brown GG, Paulus M, Martinez A, Stewart SE, Dubowitz DJ, Braff DL (2002) Neural correlates of refixation saccades and antisaccades in normal and schizophrenia subjects. Biol Psychiatry 51:216-223.

McPeek RM, Keller EL (2002) Saccade target selection in the superior colliculus during a visual search task. J Neurophysiol 88:2019-2034.

Medalla M, Barbas H (2009) Synapses with inhibitory neurons differentiate anterior cingulate from dorsolateral prefrontal pathways associated with cognitive control. Neuron 61:609-620.

Miller EK, Cohen JD (2001) An integrative theory of prefrontal cortex function. Annu Rev Neurosci 24:167-202.

Moseley JI, Ojemann GA, Ward AA Jr (1972a) Unit activity during focal cortical hypothermia in the normal cortex. Exp Neurol 37:152-163.

Moseley JI, Ojemann GA, Ward AA Jr (1972b) Unit activity in experimental epileptic foci during focal cortical hypothermia. Exp Neurol 37:164-178.

Munoz DP, Everling S (2004) Look away: the anti-saccade task and the voluntary control of eye movement. Nat Rev Neurosci 5:218-228.

Munoz DP, Wurtz RH (1995) Saccade-related activity in monkey superior 
colliculus. I. Characteristics of burst and buildup cells. J Neurophysiol 73:2313-2333.

Pierrot-Deseilligny C, Rivaud S, Gaymard B, Agid Y (1991) Cortical control of reflexive visually-guided saccades. Brain 114:1473-1485.

Pierrot-Deseilligny C, Müri RM, Ploner CJ, Gaymard B, Demeret S, RivaudPechoux S (2003) Decisional role of the dorsolateral prefrontal cortex in ocular motor behaviour. Brain 126:1460-1473.

Ploner CJ, Gaymard BM, Rivaud-Péchoux S, Pierrot-Deseilligny C (2005) The prefrontal substrate of reflexive saccade inhibition in humans. Biol Psychiatry 57:1159-1165.

Rainer G, Asaad WF, Miller EK (1998) Selective representation of relevant information by neurons in the primate prefrontal cortex. Nature 393:577-579.

Richmond BJ, Optican LM (1987) Temporal encoding of two-dimensional patterns by single units in primate inferior temporal cortex. II. Quantification of response waveform. J Neurophysiol 57:147-161.

Sakai K (2008) Task set and prefrontal cortex. Annu Rev Neurosci $31: 219-245$

Schiller PH, Chou IH (1998) The effects of frontal eye field and dorsomedial frontal cortex lesions on visually guided eye movements. Nat Neurosci $1: 248-253$.

Schlag-Rey M, Amador N, Sanchez H, Schlag J (1997) Antisaccade performance predicted by neuronal activity in the supplementary eye field. Nature 390:398-401.

Shindy WW, Posley KA, Fuster JM (1994) Reversible deficit in haptic delay tasks from cooling prefrontal cortex. Cereb Cortex 4:443-450.

Somogyi P, Tamás G, Lujan R, Buhl EH (1998) Salient features of synaptic organisation in the cerebral cortex. Brain Res Brain Res Rev 26:113-135.

Sooksawate T, Isa K, Behan M, Yanagawa Y, Isa T (2011) Organization of
GABAergic inhibition in the motor output layer of the superior colliculus. Eur J Neurosci 33:421-432.

Sweeney JA, Mintun MA, Kwee S, Wiseman MB, Brown DL, Rosenberg DR, Carl JR (1996) Positron emission tomography study of voluntary saccadic eye movements and spatial working memory. J Neurophysiol 75:454-468.

Thevarajah D, Mikulić A, Dorris MC (2009) Role of the superior colliculus in choosing mixed-strategy saccades. J Neurosci 29:1998-2008.

Thompson KG, Hanes DP, Bichot NP, Schall JD (1996) Perceptual and motor processing stages identified in the activity of macaque frontal eye field neurons during visual search. J Neurophysiol 76:4040-4055.

Walker R, Husain M, Hodgson TL, Harrison J, Kennard C (1998) Saccadic eye movement and working memory deficits following damage to human prefrontal cortex. Neuropsychologia 36:1141-1159.

Wardak C, Olivier E, Duhamel JR (2002) Saccadic target selection deficits after lateral intraparietal area inactivation in monkeys. J Neurosci 22:9877-9884.

Wardak C, Ibos G, Duhamel JR, Olivier E (2006) Contribution of the monkey frontal eye field to covert visual attention. J Neurosci 26:4228-4235.

Watanabe M, Munoz DP (2009) Neural correlates of conflict resolution between automatic and volitional actions by basal ganglia. Eur J Neurosci 30:2165-2176.

White EL (1989) Cortical circuits. Synaptic organization of the cerebral cortex. Structure, function and theory. Boston: Birkhäuser.

White IM, Wise SP (1999) Rule-dependent neuronal activity in the prefrontal cortex. Exp Brain Res 126:315-335.

Wurtz RH, Goldberg ME (1989) The neurobiology of saccadic eye movements. Amsterdam: Elsevier.

Yoshida A, Tanaka M (2009) Enhanced modulation of neuronal activity during antisaccades in the primate globus pallidus. Cereb Cortex 19:206-217. 